\title{
New Fluorescent Blue OLED Host and Dopant Materials Based on the Spirobenzofluorene
}

\author{
In-Ho Lee and Myoung-Seon Gong* \\ Department of Nanobiomedical Science and WCU Research Center of Nanobiomedical Science, Dankook University, Cheonan, \\ Chungnam 330-714, Korea. E-mail: msgong@dankook.ac.kr \\ Received January 3, 2011, Accepted March 2, 2011
}

\begin{abstract}
New spiro[benzo[c]fluorene-7,9'-fluorene] (SBFF)-based blue host materials, 9-phenyl-SBFF (BH-4P) and 5,9-diphenyl-SBFF (BH-6DP), were successfully prepared by spiro-formation of 9-phenyl-7H-benzo[c]fluoren7-one with 2-bromobiphenyl via lithiation and reaction of 5,9-dibromo-SBFF with phenylboronic acid through the Suzuki reaction, respectively. Diphenyl-[4-(2-[1,1;4,1]terphenyl-4-yl-vinyl)-phenyl]-amine (BD-1) and $N, N$-diphenyl- $N^{\prime}, N^{\prime}$-diphenyl-SBFF-5,9-diamine (BD-6DPA) were used as dopant materials. Blue OLEDs with the configuration ITO/ $N, N^{\prime}$-bis-[4-(di-m-tolylamino)phenyl]- $N, N^{\prime}$-diphenylbiphenyl-4,4'-diamine (DNTPD)/ bis[ $N$-(1-naphthyl)- $N$-phenyl]benzidine (NPB)/host:5\% dopant/SFC-137/Al-LiF were prepared from the two host materials doped with BD-1 and BD-6DPA dopants and the devices composed of BH-4P and BH-6DP doped with BD-6DPA showed blue EL spectra at 458 and $463 \mathrm{~nm}$ at $7 \mathrm{~V}$ and luminance efficiencies of 4.58 and $4.88 \mathrm{~cd} / \mathrm{A}$, respectively.
\end{abstract}

Key Words : Spiro[benzo[c]fluorene-7,9'-fluorene], Fluorescent, Host, Dopant, Deep blue

\section{Introduction}

Organic light emitting diodes (OLEDs) have attracted considerable attention due to their many advantages for use in commercial applications, including their high brightness, low power consumption, capability of emitting a wide range of colors, and applications in full color organic displays. ${ }^{1-5}$ For full color displays, three primary colors, such as red, green, and blue are necessary. Many new materials with red, green, and blue emitting colors have been developed to meet these requirements. ${ }^{6-14}$ Development of blue light emitters is essential for exploiting full color displays. However, despite many relevant studies related to blue phosphorescent devices, attainment of high efficiency and long lifetime blue phosphorescent devices is very difficult. Therefore, blue fluorescent material is still of prime importance for application in full-color flat-panel displays. To date, several derivatives of anthracene, ${ }^{15}$ binaphthol, ${ }^{16,17}$ spirobifluorene-linked bianthracene, ${ }^{18-21}$ and spirofluorenebenzofluorene ${ }^{22-29}$ have been developed and subsequent attempts were made to improve their electroluminescent (EL) properties.

Spiro-type derivatives containing fluorene and benzofluorene as OLED fluorescent materials have received a great deal of attention because asymmetrical spiro compounds having a naphthalene group can not only preserve the inherent characteristics of a spiro compound, such as morphological stability, high glass transition temperature, and amorphous properties, but also provide a variety of substituents on the aromatic ring of spiro molecules and result in formation of conjugation-controlled OLED host and dopant materials. ${ }^{22-32}$

Many studies have dealt with spiro[benzo[c]fluorene-7,9'fluorene] (SBFF) as an organic electroluminescent host and dopant material. Derivatives of 5-, 9- and both 5- and 9- on SBFF by substitution of aromatic moieties with various conjugation lengths were estimated. However, preparation of SBFF substituted at only the 9-position is extremely difficult due to lower reactivity than that of the naphthyl moiety of the electrophilic substitution reaction (bromination), as shown in Scheme 1. However, it is not satisfactory for the 2- and 5-positioned SBFFs to give full play to their characteristics regarding luminescence efficiency and color purity. Thus, the aim was to improve the performance of OLEDs host materials based on spiro[benzo[c]fluorene-7,9'fluorene], as the position of substitution and aryl substituent with a variety of conjugation chains determine the color purity and luminescence efficiency of the OLEDs devices. ${ }^{20}$

In this study, we report on the synthesis of new host materials 9-phenyl- SBFF (BH-4P) and 5,9-diphenyl-SBFF (BH-6DP), and dopant material $N, N$-diphenyl- $N^{\prime}, N^{\prime}$-diphenylSBFF-5,9-diamine (BD-6DPA) by substitution at the 5- and 9-position on SBFF by a Suzuki reaction and an amination reaction. Various properties, such as UV-vis absorption, photoluminescence, and electroluminescence, including EL efficiency and color purity, were evaluated.

\section{Experimental}

Materials and Measurements. Ethyl 2-(1-bromonaphthalene) carboxylate (1) and 5,9-dibromo-SBFF (2) were prepared by previously-reported methods. ${ }^{35,36}$ Tetrakis(triphenylphosphine)palladium(0) and 4-biphenylboronic acid, phenylboronic acid, 2-bromobiphenyl (TCI Chem. Co.), hydrochloric acid, potassium carbonate, sodium hydroxide, butyl lithium $2.5 \mathrm{M}$ solution in hexanes (Aldrich Chem. Co.), methane sulfonic acid, and sodium bicarbonate were 
used without further purification. Tetrahydrofuran (THF) and toluene were distilled over sodium and calcium hydride.

${ }^{1} \mathrm{H}-\mathrm{NMR}$ and ${ }^{13} \mathrm{C}$-NMR spectra were recorded on Varian Unity Inova (200 MHz) and Bruker Avance 500 (500 MHz) spectrometers. Photoluminescence (PL) spectra were recorded on a fluorescence spectrophotometer (Jasco FP-6500), and UV-vis spectra were obtained by means of a UV-vis spectrophotometer (Shimadzu, UV-1601PC). Energy levels were measured with a low-energy photo-electron spectrometer (Riken-Keiki AC-2). FT-IR spectra were obtained with a Thermo Fisher Nicolet 850 spectrophotometer, and elemental analyses were performed using a CE Instrument EA1110. DSC measurements were performed on a Shimadzu DSC-60 differential scanning calorimeter under nitrogen at a heating rate of $10{ }^{\circ} \mathrm{C} / \mathrm{min}$. TGA measurements were performed on a Shimadzu TGA-50. Thermogravimetric analyzer at a heating rate of $5{ }^{\circ} \mathrm{C} / \mathrm{min}$. Low- and high-resolution mass spectra were recorded using a JEOL JMS-AX505WA spectrometer in FAB mode.

Synthesis of Ethyl 1-(4-biphenyl)-2-naphthalene carboxylate (3). A solution of 1 (8.34 g, $0.03 \mathrm{~mol})$, 4-biphenylboronic acid (5.94 g, $0.03 \mathrm{~mol})$ and tetrakis(triphenylphosphine)palladium(0) (1.7 g, $1.46 \mathrm{mmol})$ dissolved in THF $(100 \mathrm{~mL})$ was stirred in a two-necked flask under a nitrogen atmosphere for $30 \mathrm{~min}$. A solution of potassium carbonate $(1.63 \mathrm{~g}, 11.18 \mathrm{mmol})$ in distilled water $(50 \mathrm{~mL})$ was added dropwise to the above reaction mixture over a period of 20 min. The resulting mixture was refluxed overnight at $80{ }^{\circ} \mathrm{C}$. The reaction mixture was extracted with dichloromethane and water. Following evaporation of the organic layer with a rotary evaporator, the resulting powdery product was purified by column chromatography from dichloromethane/ $n$-hexane (1/1) to give a white crystalline product.

FT-IR $\left(\mathrm{KBr}, \mathrm{cm}^{-1}\right.$ ) 3055, 3018, 2910, 2875, 1736 (aromatic$\mathrm{C}-\mathrm{H}) .{ }^{1} \mathrm{H}$ NMR $\left(200 \mathrm{MHz}, \mathrm{CDCl}_{3}, \mathrm{ppm}\right) 8.71(\mathrm{~d}, J=2.0 \mathrm{~Hz}$, $1 \mathrm{H}$ of naphthalene), $8.46(\mathrm{~d}, J=1.8 \mathrm{~Hz}, 1 \mathrm{H}$ of naphthalene), 8.17-7.66 (m, 3H of naphthalene), 7.25 (s, $4 \mathrm{H},-P h-\mathrm{Ph}) 7.25-$ $7.51(\mathrm{~m}, 5 \mathrm{H},-\mathrm{Ph}-\underline{P h}), 4.19$ (q, $\left.2 \mathrm{H},-\underline{\mathrm{C}}_{2} \mathrm{CH}_{3}\right), 1.28(\mathrm{t}, 3 \mathrm{H}$, $-\mathrm{CH}_{2} \mathrm{C}_{3}$ ). MS (FAB) $m / z 352.16\left[(\mathrm{M}+1)^{+}\right]$. Anal. Calcd for $\mathrm{C}_{25} \mathrm{H}_{20} \mathrm{O}_{2}$ (352.15): C, 85.20; H, 5.72. Found: C, 85.66; H, 5.71 .

Synthesis of 9-Phenyl-7H-benzo[c]fluoren-7-one (4). Compound 3 (10.56 g, $0.03 \mathrm{~mol}$ ) was dissolved by portions in methanesulfonic acid $(300 \mathrm{~mL})$. The red mixture was stirred for $24 \mathrm{~h}$ at $30{ }^{\circ} \mathrm{C}$. It was then poured into ice water. After the red precipitate was filtered and washed with water, the resulting powder was stirred in $\mathrm{NaHCO}_{3}$ solution for $3 \mathrm{~h}$. The precipitate was filtered again and washed with water until the $\mathrm{pH}$ was neutral. The powdery product was recrystallized from $\mathrm{AcOH}$ to give pure products as a red crystal.

Yield 70\%. FT-IR (KBr, cm ${ }^{-1}$ ) 3060, 3017(aromatic-C-H), $1760(\mathrm{C}=\mathrm{O}) .{ }^{1} \mathrm{H}-\mathrm{NMR}\left(200 \mathrm{MHz}, \mathrm{CDCl}_{3}, \mathrm{ppm}\right)$ 7.24-8.55 (m, $6 \mathrm{H}$ of naphthalene), 7.44-8.42 (m, 3H of $-\mathrm{CO}-\mathrm{Ph}-\mathrm{Ph})$, 7.41-7.52 (m, 5H of -CO-Ph- $\underline{P h}$ ). MS (FAB) $\mathrm{m} / z$ 306.10 $\left[(\mathrm{M}+1)^{+}\right]$. Anal. Calcd for $\mathrm{C}_{23} \mathrm{H}_{14} \mathrm{O}$ (306.16): C, 90.17; $\mathrm{H}$, 5.22. Found: C, 90.13; H, 5.18 .
Synthesis of 9-Phenyl-SBFF (BH-4P). 2-Bromobiphenyl (7.88 g, $34.0 \mathrm{mmol})$ dissolved in THF $(120 \mathrm{~mL})$ was added to a two-necked flask. The reaction flask was cooled to $-78{ }^{\circ} \mathrm{C}$ and $n$-BuLi (2.5 M in hexane, $15.6 \mathrm{~mL}$ ) was added dropwise for $10 \mathrm{~min}$. The whole solution was stirred at this temperature for $1 \mathrm{~h}$, followed by addition of a solution of $\mathbf{4}$ (7.96 g, $26.0 \mathrm{mmol})$ in THF $(150 \mathrm{~mL})$ under an argon atmosphere. The resulting mixture was gradually warmed to ambient temperature and quenched by saturated aqueous $\mathrm{NaHCO}_{3}(90 \mathrm{~mL})$. The mixture was extracted with dichloromethane. The combined organic layers were dried over magnesium sulfate, filtered, and evaporated under reduced pressure. The crude residue was placed in another twonecked flask and dissolved in acetic acid $(250 \mathrm{~mL})$. A catalytic amount of aqueous $\mathrm{HCl}(25 \mathrm{~mL}, 35 \mathrm{wt} \%)$ was then added and the whole solution was refluxed for $12 \mathrm{~h}$. After cooling to ambient temperature and purification by silica gel chromatography using dichloromethane/n-hexane $(1 / 2)$, a white powder was obtained.

Yield 92\%. mp $224{ }^{\circ} \mathrm{C}$. FT-IR (KBr, cm $\left.{ }^{-1}\right)$ 3060, 3019, 3012 (aromatic C-H). ${ }^{1} \mathrm{H}$ NMR $\left(500 \mathrm{MHz}, \mathrm{CDCl}_{3}\right) \delta 8.94-$ 8.92 (d, $J=6.1 \mathrm{~Hz}, 1 \mathrm{H}), 8.47-8.45$ (d, $J=6.2 \mathrm{~Hz}, 1 \mathrm{H}), 7.99$ 7.97 (d, $J=7.4 \mathrm{~Hz}, 1 \mathrm{H}), 7.84-7.82(\mathrm{~d}, J=6.2 \mathrm{~Hz}, 1 \mathrm{H}), 7.73-$ $7.70(\mathrm{t}, 2 \mathrm{H}), 7.50-7.45(\mathrm{q}, 3 \mathrm{H}), 7.35-7.30(\mathrm{~m}, 7 \mathrm{H}), 7.15-7.12$ (t, 2H), 7.10-7.07 (t, 2H), 6.81-6.79 (d, $J=7.2 \mathrm{~Hz}, 1 \mathrm{H})$, 6.76-6.75 (d, 1H), ${ }^{13} \mathrm{C} \mathrm{NMR}\left(\mathrm{CDCl}_{3}\right) \delta 149.8,148.2,142.2$, $141.1,140.8,132.4,130.2,128.2,128.1,127.6,127.3$, 127.0, 126.9, 125.6, 124.4, 124.2, 123.2, 120.1, 77.4, 77.2, 76.9, 66.5 ppm. MS (FAB) $\mathrm{m} / \mathrm{z} 442.0\left[(\mathrm{M}+1)^{+}\right]$. Anal. Calcd for $\mathrm{C}_{35} \mathrm{H}_{22}$ (442.17): C, 94.99; H, 5.01. Found: C, 94.91; $\mathrm{H}$, 4.98. UV-vis (THF): $\lambda_{\max }$ (Absorption) $=355 \mathrm{~nm}, \lambda_{\max }$ $($ Emission $)=418 \mathrm{~nm}$.

Synthesis of 5,9-Diphenyl-SBFF (BH-6DP). A solution of 2 (5.01 g, $11.23 \mathrm{mmol}$ ), phenylboronic acid (3.05 g, 25.0 $\mathrm{mmol})$ and tetrakis(triphenylphosphine)palladium $(0)(0.65$ $\mathrm{g}, 0.56 \mathrm{mmol})$ dissolved in THF $(100 \mathrm{~mL})$ was stirred in a two-necked flask under a nitrogen atmosphere for $30 \mathrm{~min}$. A solution of potassium carbonate $(1.63 \mathrm{~g}, 11.18 \mathrm{mmol})$ in distilled water $(50 \mathrm{~mL})$ was added dropwise to the above reaction mixture over a period of $20 \mathrm{~min}$. The resulting mixture was refluxed overnight at $80{ }^{\circ} \mathrm{C}$. The reaction mixture was extracted with dichloromethane and water. Following evaporation of the organic layer with a rotary evaporator, the resulting powdery product was purified by column chromatography from dichloromethane $/ n$-hexane $(1 / 2)$ to give a white powder. Yield $82 \%$. mp $270.8{ }^{\circ} \mathrm{C}$. FT-IR $\left(\mathrm{KBr}, \mathrm{cm}^{-1}\right) 3059$, 3040, 3012, 3010 (aromatic C-H). ${ }^{1} \mathrm{H}-\mathrm{NMR}(500 \mathrm{MHz}$, $\left.\mathrm{CDCl}_{3}, \mathrm{ppm}\right) \delta 8.94-8.92(\mathrm{~d}, J=6.2 \mathrm{~Hz}, 1 \mathrm{H}), 8.46-8.42(\mathrm{~d}, J$ $=6.1 \mathrm{~Hz}, 1 \mathrm{H}), 7.96-7.92(\mathrm{~d}, J=6.1 \mathrm{~Hz}, 1 \mathrm{H}), 7.84-7.80(\mathrm{~d}, J$ $=6.3 \mathrm{~Hz}, 1 \mathrm{H}), 7.74-7.70(\mathrm{t}, 2 \mathrm{H}), 7.50-7.44(\mathrm{q}, 3 \mathrm{H}), 7.35-$ $7.30(\mathrm{~m}, 7 \mathrm{H}), 7.15-7.12(\mathrm{t}, 4 \mathrm{H}), 7.10-7.06(\mathrm{t}, 4 \mathrm{H}), 6.82-6.80$ $(\mathrm{d}, J=6.0 \mathrm{~Hz}, 1 \mathrm{H}), 6.76-6.75(\mathrm{~d}, J=6.3 \mathrm{~Hz}, 1 \mathrm{H}) .{ }^{13} \mathrm{C}-\mathrm{NMR}$ $\left(500 \mathrm{MHz}, \mathrm{CDCl}_{3}\right)$ 149.9, 148.3, 142.2, 141.2, 140.8, 140.1, $132.4,131.3,130.2,128.3,128.2,127.6,127.4,127.0$, 126.8, 126.4, 125.5, 124.4, 124.2, 124.0, 123.3, 120.2, 77.4, 77.2, 76.8, 66.5 ppm. MS (FAB) $m / z 518.18\left[(\mathrm{M}+1)^{+}\right]$. Anal. Calcd. for $\mathrm{C}_{41} \mathrm{H}_{26}$ (518.20): C, 94.95; H, 5.05. Found: C, 
95.86; H, 5.02. UV-vis (THF): $\lambda_{\max }$ (Absorption) $=362 \mathrm{~nm}$, $\lambda_{\max }($ Emission $)=420 \mathrm{~nm}$.

Preparation of $N, N, N^{\prime}, N^{\prime}$-tetraphenyl-SBFF-5,9-diamine (BD-6DPA). The 5,9-dibromo-SBFF (5 g, $9.53 \mathrm{mmol})$, diarylamine derivative $(24.79 \mathrm{mmol})$ and palladium acetate $(0.150 \mathrm{~g}, 0.67 \mathrm{mmol})$ were dissolved in anhydrous toluene under a nitrogen atmosphere. A solution of tri-t-butylphosphine $(1 \mathrm{M}, 0.42 \mathrm{~g}, 1.91 \mathrm{mmol})$ and potassium $t$-butoxide (4.28 g, $38.15 \mathrm{mmol}$ ) was slowly added dropwise to the reaction mixture. The reaction mixture was stirred for $12 \mathrm{~h}$ at $100{ }^{\circ} \mathrm{C}$. The mixture was diluted with dichloromethane and washed with distilled water $(150 \mathrm{~mL})$ three times. The organic layer was dried over anhydrous $\mathrm{MgSO}_{4}$ and evaporated in vacuo to give the crude product, which was purified by column chromatography by $n$-hexane. The final product was obtained, a yellow-green powder.

BD-6DPA: Yield 65\%. mp $270{ }^{\circ} \mathrm{C} .{ }^{1} \mathrm{H}$ NMR $(500 \mathrm{MHz}$, $\left.\mathrm{CDCl}_{3}\right) \delta 8.77-8.76(\mathrm{~d}, J=6.40 \mathrm{~Hz}, 1 \mathrm{H}, \mathrm{Ar}-\mathrm{CH}-$ naphthalene $)$, 8.23-8.22 (d, $J=6.54 \mathrm{~Hz}, 1 \mathrm{H}$, Ar-CH-naphthalene), 8.02$8.00(\mathrm{~d}, J=6.37 \mathrm{~Hz}, 1 \mathrm{H}$, Ar-CH-benzene), 7.69-7.67 (d, $J=$ 6.61 Hz, 2H, Ar-CH-fluorene), 7.61-7.59 (t, 1H, Ar-CHnaphthalene), 7.39-7.38 (t, Ar-CH-naphthalene), 7.28-7.26 (t, Ar-CH-fluorene), 7.12-7.10 (s, 2H, Ar-CH-benzene), 7.127.10 (t, 4H, Ar-CH-benzene), 7.10-7.08 (d, 2H, Ar-CHfluorene), 6.96-6.94 (t, 4H, Ar-CH-benzene), 6.90-6.89 (t, 4H, Ar-CH-benzene), 6.89-6.87 (d, 1H, Ar-CH-naphthalene), 6.82-6.81 (d, 4H, Ar-CH-benzene), 6.71-6.69 (d, 1H, Ar-CH-benzene), $6.56-6.56$ (d, $1 \mathrm{H}$, Ar-CH-benzene). ${ }^{13} \mathrm{C}$ NMR $\left(\mathrm{CDCl}_{3}\right) \delta 151.6,148.0,147.9,147.8,147.5,146.8$, $142.7,142.1,137.1,135.4,131.9,130.8,129.2,127.9,127.8$, $127.0,126.1,125.7,124.4,124.1,123.9,123.5,123.4,122.9$, 121.5, 121.4, 120.3. 119.5, 77.4, 77.2, 76.9, 66.4 ppm. MS (FAB) $m / z \quad 700.29\left[(\mathrm{M}+1)^{+}\right]$. Anal. Calcd. for $\mathrm{C}_{53} \mathrm{H}_{36} \mathrm{~N}_{2}$ (700.29): C, 90.83; H, 5.18. Found: C, 90.78; H, 5.14. UV$\operatorname{vis}(\mathrm{THF}): \lambda_{\max }($ Absorption $)=407 \mathrm{~nm}, \lambda_{\max }($ Emission $)=478$ $\mathrm{nm}$.

OLED Fabrication and Measurement. Prior to device fabrication, ITO with a resistance of $12 \Omega / \square$ on glass was patterned as an active area of $4 \mathrm{~mm}^{2}(2 \mathrm{~mm} \times 2 \mathrm{~mm})$. The substrates were cleaned by sonication in deionized water, boiled in IPA for $20 \mathrm{~min}$, and dried with nitrogen. Finally, the substrates were dry-cleaned using plasma treatment in an $\mathrm{O}_{2}$ and $\mathrm{Ar}$ environment. Organic layers were deposited onto the substrate sequentially by thermal evaporation from resistively heated alumina crucibles at a rate of $1.0 \AA / \mathrm{s}$. The thicknesses of the $N, N^{\prime}$-bis-[4-(di- $m$-tolylamino)phenyl]$N, N^{\prime}$-diphenylbiphenyl-4,4-diamine (DNTPD, HIL), bis[N(1-naphthyl)- $N$-phenyl]benzidine (NPB, HTL), host: $5 \%$ dopant (EML) and SFC-137 (ETL) layers were about 500, 300,300 , and $500 \AA$, respectively, as shown in Figure 1. Before deposition of the metal cathode, LiF was deposited onto the organic layers with a thickness of $10 \AA$. A highpurity aluminum cathode was deposited at a rate of 1-5 $\AA / \mathrm{s}$ with a thickness of $2000 \AA$ as the top layer. After the device was fabricated, the evaporation chamber was vented with nitrogen gas and the device was immediately transferred to a glove box. A thin epoxy adhesive was applied from a

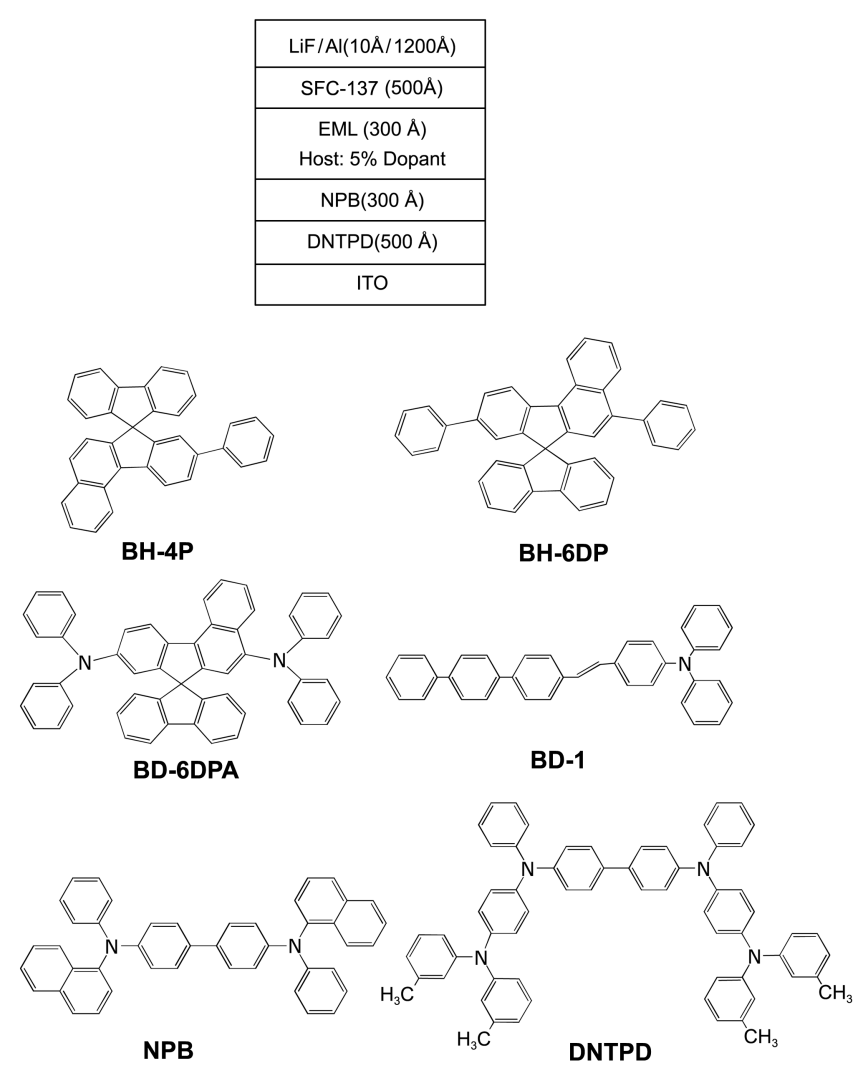

Figure 1. The device configuration and the chemical structure of the materials used in the devices.

syringe around the edge of a clean cover glass. To complete the package, a clean cover glass was placed on the top of the device. The epoxy resin was cured under intense UV radiation for $3 \mathrm{~min}$. The current-voltage characteristics of the encapsulated devices were measured on a programmable electrometer having current and voltage sources (Source Measure Unit, model Keithley 237). Luminance and EL spectra were measured with a PR650 system (Photo Research Co. Ltd.).

\section{Results and Discussion}

Synthesis and Characterization. As the benzofluorene was composed of phenyl and naphthalene moieties, preparation of 9-bromo-SBFF by direct bromination reaction of SBFF with bromine was difficult. The rate of substitution reaction of bromine on the naphthalene ring was faster than that of the phenyl ring. Thus, the multi-step synthesis was indispensable to prepare 9-phenyl-SBFF (BH-4P). BH-4P can only be achieved using a typical four-step reaction: 1) introduction of a biphenyl group to ethyl 2-(1-bromonaphthalene) carboxylate (1) by the Suzuki reaction, 2) hydrolysis of the ester group of ethyl 2-(4-biphenyl)naphthalene carboxylate (3), 3) five-membered ring formation by acid catalyzed cyclization of 2-(1-biphenylnaphthalene) carboxylic acid and 4) spiro-formation of 2-bromobiphenyl with 9phenyl-7H-benzo[c]fluoren-7-one (4) via lithiation, as shown in Scheme 1. 

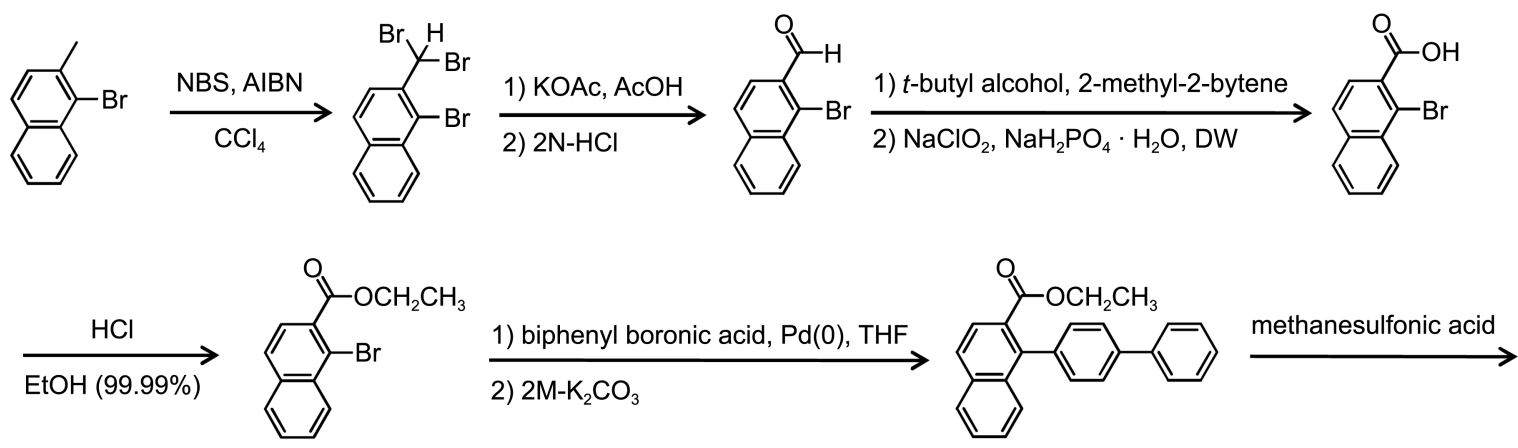

1

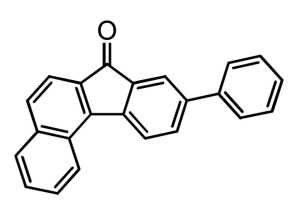

4

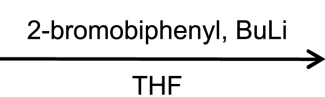

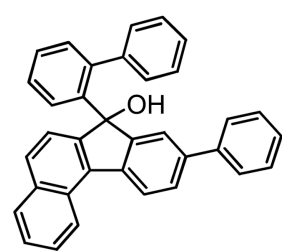

3
BH-4P

Scheme 1. Synthetic routes to host material BH-4P.

SBFF-based blue host material, BH-6DP, was successfully prepared by reaction of $\mathbf{2}$ with phenylboronic acid using a palladium catalyst, as illustrated in Scheme 2. BH4P, BH-6DP, and BD-6DPA were characterized by ${ }^{1} \mathrm{H}-\mathrm{NMR}$, ${ }^{13} \mathrm{C}-\mathrm{NMR}$, and FT-IR spectroscopy. All of the proton peaks were observed in the range of 6.71-8.93 ppm, of which the coupling constants could not be distinguished in the ${ }^{1} \mathrm{H}$ NMR spectra of three host materials and the chiral carbon peak was observed at $66.5 \mathrm{ppm}$ in the ${ }^{13} \mathrm{C}$ NMR spectra. Results of the elemental analysis and mass spectroscopy also supported formation of two host and dopant materials and matched well with the calculated data. The dopant material, BD-6DPA, was prepared by amination reaction of compound $\mathbf{2}$ with diphenylamine in the presence of a palladium catalyst. The synthetic route to the dopant material is described in Scheme 2.

Thermal Properties. Degradation of organic optoelectronic devices depends on morphological changes resulting from the thermal stability of the amorphous organic layer. The thermal properties of the newly synthesized host
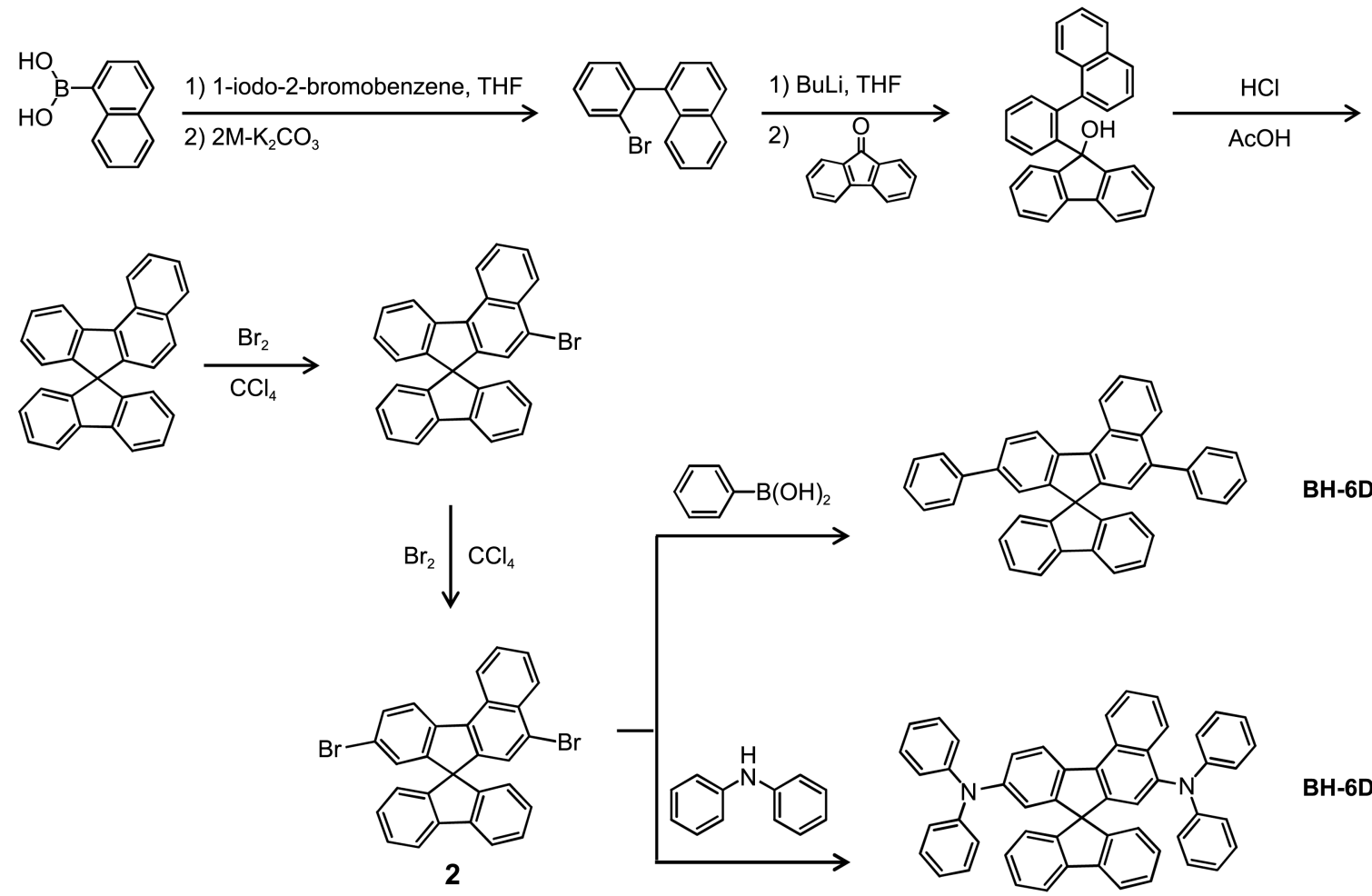

BH-6DP

BH-6DPA

Scheme 2. Synthetic routes to host and dopant material BH-6DP and BH-6DPA. 
materials were investigated by DSC and TGA analysis in a nitrogen atmosphere. Onset decomposition temperatures were 393,402 , and $429^{\circ} \mathrm{C}$ for BH-4P, BH-6DP, and BHDPA, respectively. Table 1 summarizes the DSC and TGA data for the two host and dopant materials. Purified samples of BH-4P, BH-6DP, and BH-6DPA showed a melting point $\left(T_{m}\right)$ of $224,240.8$, and $270{ }^{\circ} \mathrm{C}$, respectively. On the second heating, no melting points were observed, even though it was given enough time to cool in air. Once it became an amorphous solid, it did not revert to the crystalline state at all. After the sample had cooled to room temperature, a second DSC scan performed at $10{ }^{\circ} \mathrm{C} / \mathrm{min}$ revealed a $\mathrm{T}_{\mathrm{g}}$ at 115,129 , and $120^{\circ} \mathrm{C}$, respectively, which are two times that of DPVBi $\left(64^{\circ} \mathrm{C}\right)$ and similar to that of $\operatorname{MADN}\left(120^{\circ} \mathrm{C}\right)$. As a result, the amorphous glassy state films of the two host and dopant materials were good candidates as EL materials.

Optical Properties and Energy Levels. The UV and PL spectra of the synthesized compounds in THF solution and in thin films are shown in Table 1 and Figure 2. In solution, BH-4P and BH-6DP had a UV max $_{\text {max }}$ of 355 and 362 and a blue $\mathrm{PL}_{\max }$ of about 418 and $424 \mathrm{~nm}$. However, BH-6DPA had a $\mathrm{UV}_{\max }$ of $407 \mathrm{~nm}$ and a $\mathrm{PL}_{\max }$ of $478 \mathrm{~nm}$, indicating a red shift of about 45-52 nm relative to BH-4P and BH-6DP. The PL spectra of BH-4P and BH-6DP in thin films, fabricated by vacuum deposition, showed in the blue region at 428 and $437 \mathrm{~nm}$, and BH-6DPA had a $\mathrm{PL}_{\max }$ at $484 \mathrm{~nm}$. All three synthesized compounds showed a PL wavelength that was red shifted about 6-13 nm in solution compared to the film. Since there is a $\pi-\pi^{*}$ interaction between molecules in a film, this state typically shows red shifts relative to molecules in solution.

The energy levels of two host and dopant materials used in fabrication of OLEDs in the present study are shown in Figure 2 and Table 1. A low-energy photoelectron spectrometer was used to obtain information on the HOMO energies of the host and dopant materials and to examine the charge injection barriers. The HOMO energy levels of host and dopant materials were determined to be $5.87,5.81$, and $5.48 \mathrm{eV}$ for BH-4P, BH-6DP, and BD-6DPA, respectively,

Table 1. The various properties of BH-1P, BH-6DP and BD-6DPA

\begin{tabular}{|c|c|c|c|c|c|}
\hline Properties & Instrument & Units & $\mathrm{BH}-4 \mathrm{P}$ & BH-6DP & BD-6DPA \\
\hline \multirow{3}{*}{$\begin{array}{l}\text { Thermal } \\
\text { analysis }\end{array}$} & \multirow{2}{*}{ DSC } & $T_{g}{ }^{a}\left({ }^{\circ} \mathrm{C}\right)$ & 115 & 129 & 120 \\
\hline & & $T_{m}{ }^{b}\left({ }^{\circ} \mathrm{C}\right)$ & 224 & 240.8 & 270 \\
\hline & TGA & $T_{d}^{c}\left({ }^{\circ} \mathrm{C}\right)$ & 393 & 402 & 429 \\
\hline \multirow{6}{*}{$\begin{array}{l}\text { Optical } \\
\text { analysis }\end{array}$} & \multirow{2}{*}{ UV } & $\lambda_{\max }(\mathrm{nm})$ & 355 & 362 & 407 \\
\hline & & $\mathrm{Bg}^{d}(\mathrm{eV})$ & 3.34 & 3.25 & 2.71 \\
\hline & \multirow{2}{*}{ PL } & $\lambda_{\max }(\mathrm{nm})$ & 418 & 424 & 478 \\
\hline & & $\mathrm{FWHM}^{e}(\mathrm{~nm})$ & 29.7 & 38.1 & 39.1 \\
\hline & \multirow{2}{*}{ Solid PL } & $\operatorname{Max}(\mathrm{nm})$ & 428 & 437 & 484 \\
\hline & & $\mathrm{FWHM}^{e}(\mathrm{~nm})$ & 37.8 & 37.3 & $48.0-$ \\
\hline \multirow{2}{*}{$\begin{array}{l}\text { Electrical } \\
\text { analysis }\end{array}$} & \multirow{2}{*}{ AC-2 } & $\operatorname{HOMO}^{f}(\mathrm{eV})$ & 5.87 & 5.81 & 5.48 \\
\hline & & $\mathrm{LUMO}^{g}(\mathrm{eV})$ & 2.53 & 2.56 & 2.77 \\
\hline
\end{tabular}

${ }^{a}$ Melting temperature. ${ }^{b}$ Glass transition temperature. ${ }^{c}$ Decomposition temperature. ${ }^{d}$ Band gap. ${ }^{e}$ Full width at half maximum. ${ }^{f}$ Highest occupied molecular orbital. ${ }^{g}$ Lowest unoccupied molecular orbital.
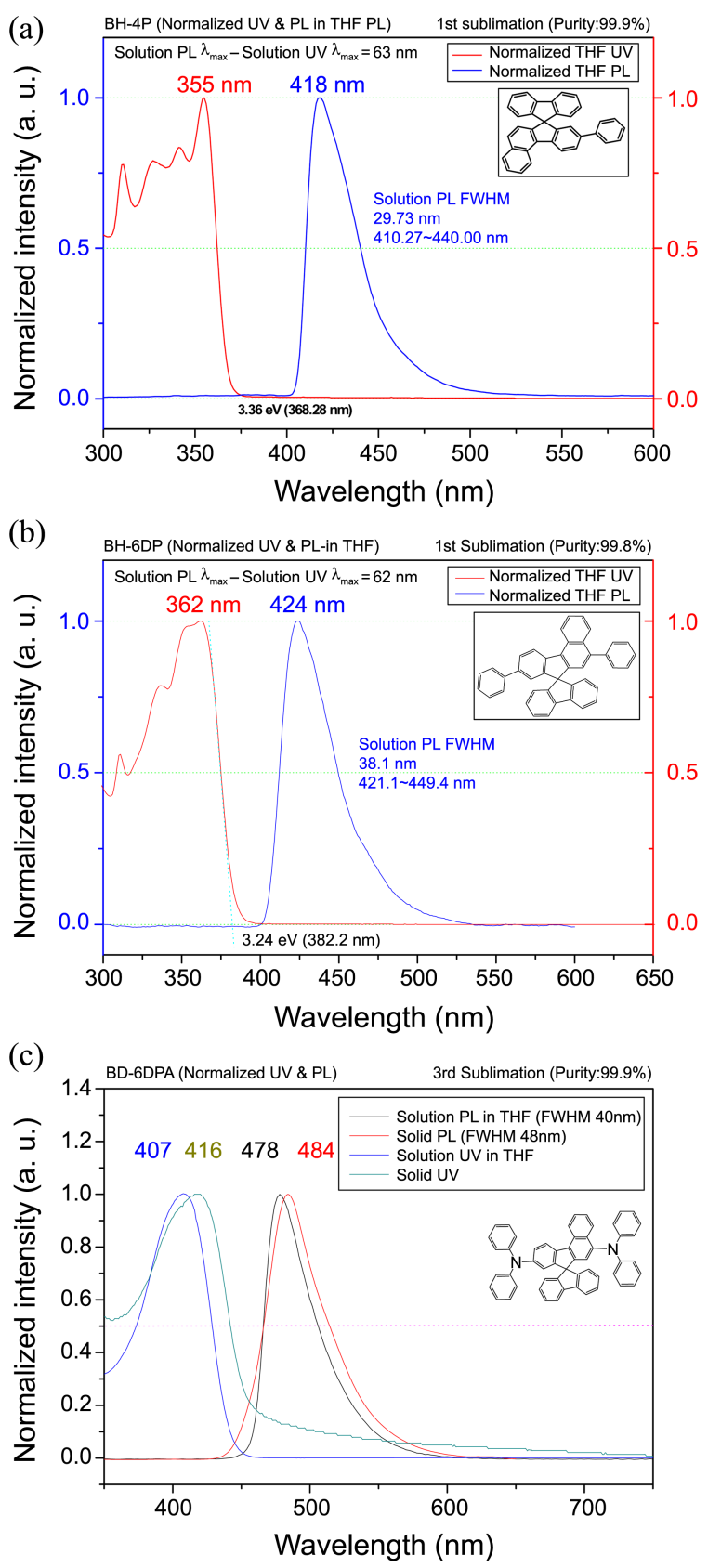

Figure 2. UV absorption and photoluminescence spectra of (a) BH-4P, (b) BH-6DP and (c) BD-6DPA in THF solution.

by low-energy photoelectron spectrometer. These HOMO values were different from the HOMO values of 5-phenylspiro[fluorene-7,9-benzofluorene] for $5.97 \mathrm{eV}$ and other MADN for 5.5-5.6 eV. ${ }^{37}$ In particular, BH-4P and BH-6DP had HOMO values about $0.3 \mathrm{eV}$ higher than that for MADN and $\beta$-ADN. ${ }^{38}$ The optical energy bandgaps, as determined from the absorption spectra of the present blue emitting films, were 3.54, and $3.25 \mathrm{eV}$ for BH-4P and BH-6DP, respectively. The energy gap for BD-6DPA was calculated as $2.71 \mathrm{eV}$.

Electroluminescence Devices. The EL properties of the BH-4P and BH-6DP host materials were examined by fabrication of multilayer devices with the following configuration: 
(a)

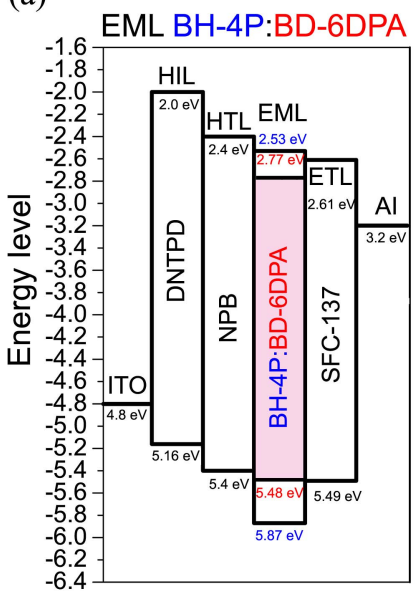

(b)

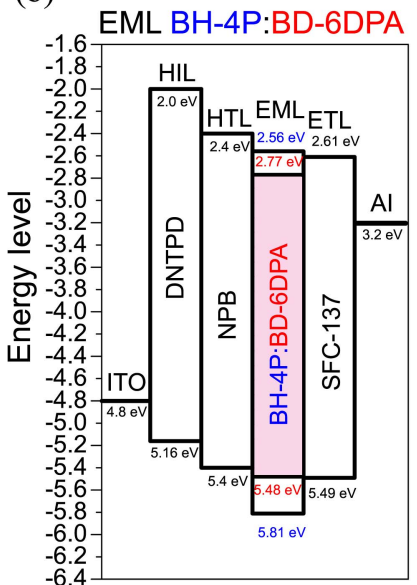

Figure 3. Energy diagram of (a) BH-4P:BD-6DPA and (b) BH6DP:BD-6DPA.

glass ITO anode/hole injection layer (HIL)/hole transfer layer (HTL)/emitting layer (EML)/electron transport layer (ETL)/electron injection layer (EIL)/Al cathode. DNTPD was used as the HIL, NPB as the HTL, host:5\% dopant as the EML, and SFC-137 as the ETL; A $10 \AA \mathrm{LiF}$ layer was used as the EIL.

Figure 4 shows the normalized EL spectra of a device
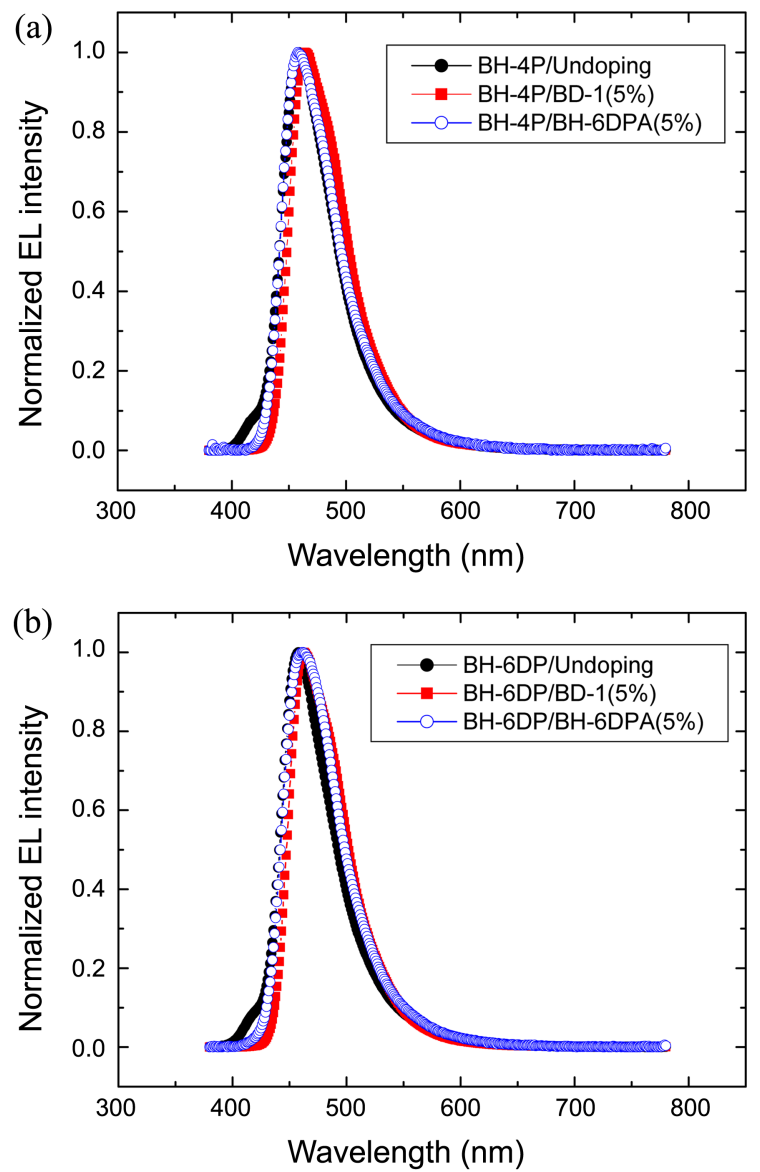

Figure 4. EL spectra of the devices obtained from BH-4P and BH6DP doped with 5\% BD-6DPA and 5\% BD-1.

composed of BH-4P and BH-6DP doped with BD-6DPA and BD- 1 with the above structure at $7 \mathrm{~V}$. All of the devices showed intense blue emission in the EL spectra between 458 $\mathrm{nm}$ and $463 \mathrm{~nm}$. The maximum wavelength of the EL spectra varied significantly according to the dopant material. Devices doped with BD-6DPA showed a 2-6 nm longer wavelength in the EL spectra than those of BD-1. The EL spectrum of the ITO/DNTPD/NPB/host:5\% dopant/SFC137/LiF/Al device showed an adequate FWHM of $54-58 \mathrm{~nm}$ and a $\lambda_{\max }=458$ and $463 \mathrm{~nm}$. These devices have a narrow FWHM, which is required for a monochromic light source. On the basis of the similar FWHM of EL spectra, we conclude that the blue EL is due to the intrinsic emission of BH-4P and BH-6DP, with a little emission interference from the dopant.

Figure 5 and 6 show the current density-voltage and luminance-voltage characteristics of the four deep-blue fluorescent devices. Devices using BH-4P had I-V characteristics similar to those of the device using BH-6DP as the emitting layer. The threshold voltage for luminescence is about $5.0 \mathrm{~V}$, at which the electrons and holes appear to reach the lightemitting layer; in all of the devices, no light emission occurs below this voltage, as shown in Figure 5. In the case of

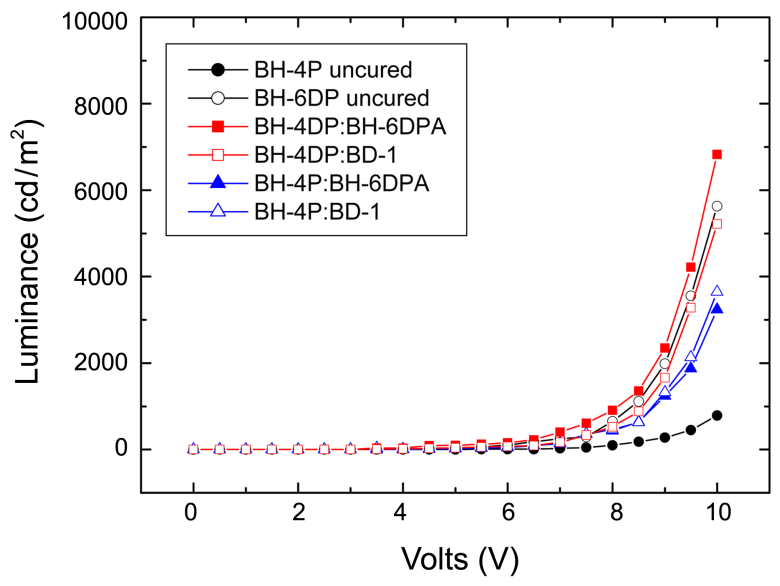

Figure 5. Luminance-voltage characteristics of the device using BH-4P and BH-6DP doped with 5\% BD-6DPA and 5\% BD-1.

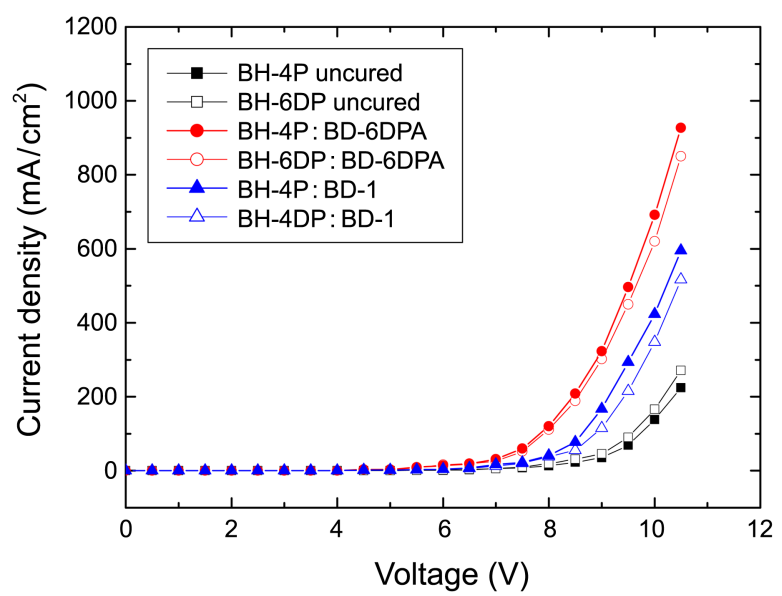

Figure 6. Current density-voltage characteristics of the device using BH-4P and BH-6DP doped with 5\% BD-6DPA and 5\% BD-1. 


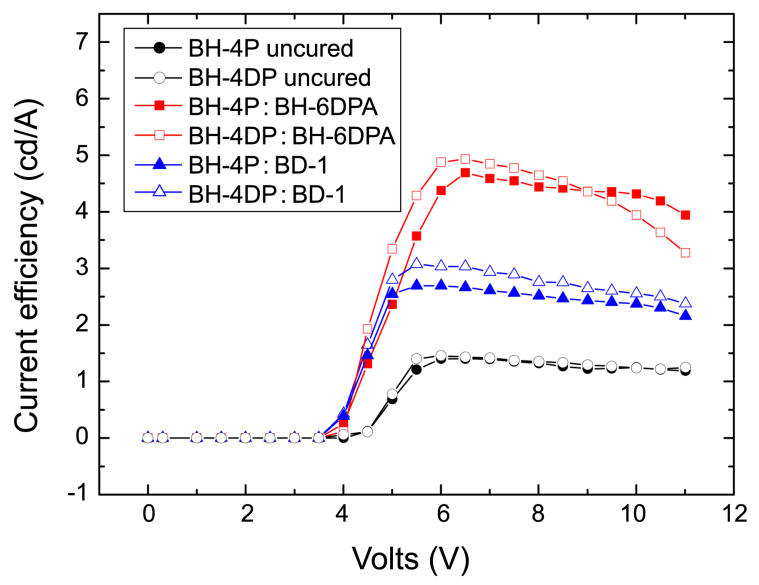

Figure 7. Efficiency-current density characteristics of the device using BH-4P and BH-6DP doped with 5\% BD-6DPA and 5\% BD-1.

Table 2. EL properties of the devices obtained from MADN host and four dopant materials at $7 \mathrm{~V}$

\begin{tabular}{|c|c|c|c|c|c|}
\hline \multirow[b]{2}{*}{ Propertie } & \multirow[t]{2}{*}{ Devices } & \multicolumn{2}{|c|}{ BH-4P } & \multicolumn{2}{|c|}{ BH-6DP } \\
\hline & & BD-6DPA & BD-1 & BD-6DPA & BD-1 \\
\hline \multirow{9}{*}{$\begin{array}{c}\text { EL } \\
\text { at } 7 \mathrm{~V}\end{array}$} & $\lambda_{\max }(\mathrm{nm})$ & 464 & 458 & 463 & 461 \\
\hline & FWHM(nm) & 54 & 55 & 55 & 58 \\
\hline & $\mathrm{mAcm}^{-2}$ & 25.2 & 12.4 & 31.1 & 17.0 \\
\hline & $\mathrm{cdA}^{-1}$ & 2.94 & 2.61 & 4.85 & 4.58 \\
\hline & $\operatorname{lm} W^{-1}$ & 1.39 & 1.17 & 2.79 & 2.59 \\
\hline & $\mathrm{cdm}^{-2}$ & 168.8 & 137.3 & 401.1 & 150.7 \\
\hline & CIE-x & 0.14 & 0.14 & 0.14 & 0.14 \\
\hline & CIE-y & 0.19 & 0.16 & 0.18 & 0.16 \\
\hline & EQE (\%) & 1.84 & 1.68 & 4.12 & 3.98 \\
\hline
\end{tabular}

devices using BH-6DP doped with 5\% BD-6DPA, the maximum brightness of $401 \mathrm{~cd} / \mathrm{m}^{2}$ occurred at approximately $7.0 \mathrm{~V}$, as shown in Figures 5, 6, and 7. All of the devices exhibited very low current density before the turn-on voltage due to the absence of shunt resistance. All of the OLEDs made using BH-4P and BH-6DP showed good performance for the two dopant materials BD-6DPA and BD-1, as detailed in Table 2.

The efficiency of the device composed of BH-6DP doped with BD-6DPA and BD-1 was much higher than that of the device with undoped BH-6DP due to the improved electron and hole balance in the device; its luminescence efficiency (LE) and external quantum efficiency (EQE) reached 4.85 $\mathrm{cd} / \mathrm{A}$ and $4.12 \%$, respectively, with CIE coordinates of $(0.14$, 0.18 ) at a current density of $31.1 \mathrm{~mA} / \mathrm{cm}^{2}$ at $7 \mathrm{~V}$, as shown in Figures 7 and 8 . The device doped with BD-1 showed an EQE of $3.98 \%$ and $\mathrm{LE}$ of $4.58 \mathrm{~cd} / \mathrm{A}$. However, the EL emission of OLEDs with the BH-6DP:5\% BD-1 showed a blue spectrum with CIE coordinate $(0.14,0.16)$. Pure deepblue EL was obtained from the device made with only BH$4 \mathrm{P}$ with CIE coordinates of $(0.14,0.14)$, which is obviously a deep-blue emission, as shown in Figure 9. Although the CIE value of the BH-6DP device was slightly different from that of the BH-4P device, its luminance efficiency and power

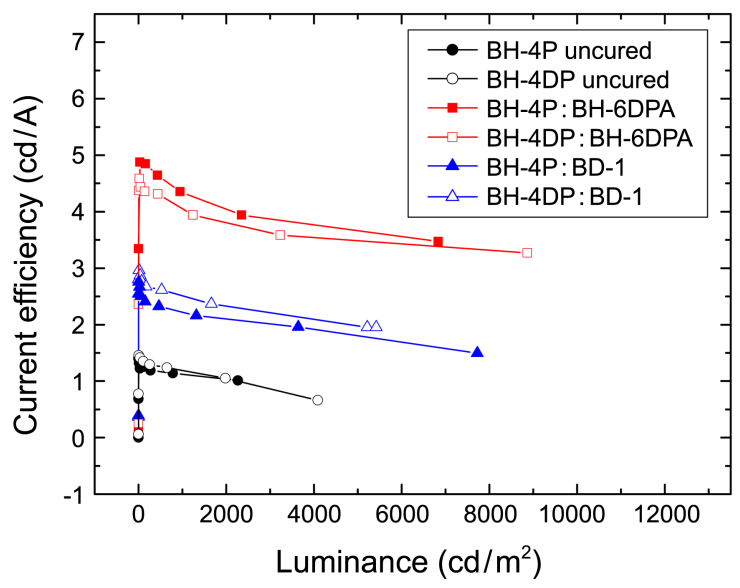

Figure 8. Efficiency-voltage characteristics of the device using BH-4P and BH-6DP doped with 5\% BD-6DPA and 5\% BD-1.

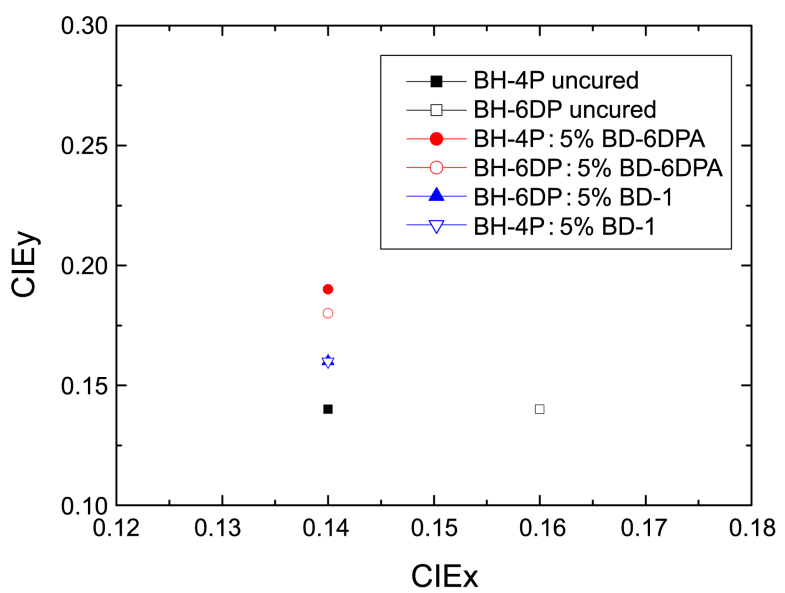

Figure 9. The CIE 1931 coordinates diagram of device obtained from BH-4P and BH-6DP doped with 5\% BD-6DPA and BD-1.

efficiency were higher than that of the BH-4P device. The BH-6DP: BD-6DPA device also had an excellent FWHM value $(55 \mathrm{~nm})$ despite its asymmetric structure. This value was lower than for the BH-6DP: BD-1 $(58 \mathrm{~nm})$ because the bulky spiro group effectively prevented $\pi-\pi$ stacking interactions between molecules.

In comparison with $\mathrm{BH}-4 \mathrm{P}, \mathrm{BH}-6 \mathrm{DP}$ composed of phenyl groups on both sides showed increased $\mathrm{cd} / \mathrm{A}$ and $\mathrm{lm} / \mathrm{W}$ resulting from a reduction in the energy barrier inside layers of devices due to formation of a relatively narrow band-gap. As a result, easier movement of hole and electron allows for lower operating voltage and higher $\mathrm{cd} / \mathrm{A}$ and $\mathrm{lm} / \mathrm{W}$.

The fine structure of the EL spectrum of BH-6DP with a peak at $464 \mathrm{~nm}$ and CIE coordinates of $x=0.14, y=0.18$ is not consistent with the PL spectra at $437 \mathrm{~nm}$. There is a strong broadening in the EL spectra, as compared with a solid PL spectrum, because the intrinsic emission of BH$6 \mathrm{DP}$ interfered with the dopant material. Although $\mathrm{BH}-4 \mathrm{P}$ and BH-6DP did not yield a better blue-light-emitting material than the two host materials $b-\mathrm{ADN}$ and MADN, it will be studied with the aim of device optimization using the other dopants, HTL and ETL. 


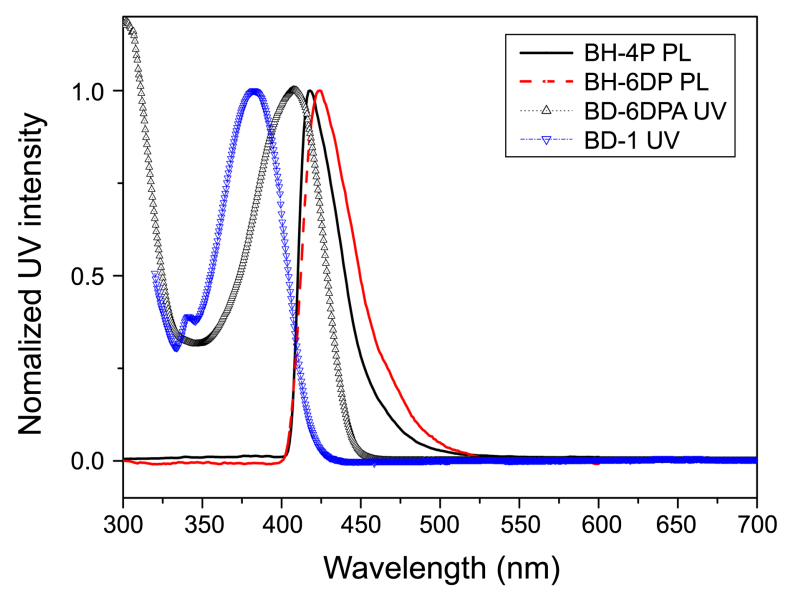

Figure 10. UV-vis absorption spectrum of BD-6DPA and BD-1 and PL spectra of the BH-4P and BH-6DP.

Figure 10 shows the absorption spectrum of BD-6DPA and BD-1 and the PL spectrum of BH-4P and BH-6DP. As shown in Figure 10 and its inset, the energy band diagram of $\mathrm{BH}-4 \mathrm{P}$ and $\mathrm{BH}-6 \mathrm{DP}$ overlaps with a major portion of the absorption spectrum of BD-6DPA and BD-1. This indicates that the BD-6DPA and BD-1 dopant can effectively accept energy from the host by Förster-type energy or function as a direct recombination center because of a higher HOMO level. In particular, the efficient energy transfer from BD6DPA to BH-6DP occurs between absorption of the dopant and emission of the host material.

\section{Conclusion}

New blue light emitting spiro-type host materials BH-4P and BH-6DP and dopant material BD-6DPA were prepared in order to construct a blue organic light-emitting diode. Devices made using BH-4P and BH-6DP as the host and BD-6DPA as the dopant showed blue light emission with a maximum EL emission at $463 \mathrm{~nm}$. An OLED made using BH-6DP as a host with the structure of ITO/DNTPD/NPB/ BH-9PA:5\% BD-6MDPA/SFC-137/Al-LiF showed luminescence efficiency (LE) reaching $4.85 \mathrm{~cd} / \mathrm{A}$ with CIE coordinates of $(0.14,0.18)$ at a current density $31.1 \mathrm{~mA} / \mathrm{cm}^{2}$ at $7 \mathrm{~V}$. According to these characteristics, some of these deep-blue emitting materials have sufficient potential for use in display applications.

\section{References}

1. Burroughes, J. H.; Bradley, D. D. C.; Brown, A. R.; Marks, R. N.; Mackay, K.; Friend, R. H.; Burns, P. L.; Holmes, A. B. Nature 1990, 347, 539 .

2. Tang, C. W.; VanSlyke, S. A. Appl. Phys. Lett. 1987, 51, 913.

3. Hung, L. S.; Chen, C. H. Mat. Sci. Eng. 2002, 39, 143.

4. Mitschke, U.; Bäuerle, P. J. Mater. Chem. 2000, 10, 1471.

5. Shirota, Y. J. Mater. Chem. 2000, 10, 1.

6. Chen, C. H.; Tang, C. W.; Shi, J.; Klubek, K. P. Thin Solid Films 2000, 363, 327.
7. Wang, P.; Hong, Z.; Xie, Z. Tong, S.; Wong, O.; Lee, C. S.; Wong, N.; Hung, L.; Lee, S. Chem. Commun. 2003, 14, 1664.

8. Cheng, G.; Zhang, Y. F.; Zhao, Y.; Liu, S. Y.; Tang, S.; Ma, Y. G. Appl. Phys. Lett. 2005, 87, 151905.

9. Shen, W. J.; Dodda, R.; Wu, C. C.; Wu, F.; Liu, T. H.; Chen, C. H.; Shu, C. F. Chem. Mater. 2004, 16, 930-934.

10. Tao, S.; Hong, Z.; Peng, Z.; Ju, W.; Zhang, X.; Wang, P.; Wu, S.; Lee, S. Chem. Phys. Lett. 2004, 397, 1.

11. Shih, H. T.; Lin, C. H.; Shin, H. H.; Cheng, C. H. Adv. Mater. 2002, 14, 1409.

12. Danel, K.; Huang, T. H.; Lin, J. T.; Tao, Y. T.; Chuen, C. H. Chem. Mater. 2002, 14, 3860.

13. Kim, Y. H.; Jeong, H. C.; Kim, S. H.; Yang, K.; Kwon, S. K. $A d v$. Funct. Mater. 2005, 15, 1799.

14. Huang, C.; Zhen, C. G.; Su, S. P.; Loh, K. P.; Chen, Z. K. Org lett. 2005, 7, 391.

15. Shih, P. I.; Chuang, C. Y.; Chien, C. H.; Diau, E. W. G.; Shu, C. F. Adv. Funct. Mater. 2007, 17, 3141.

16. Shi, J.; Tang, C. W. Appl. Phys. Lett. 2002, 80, 3201.

17. Wei, B.; Liu, J. Z.; Zhang, Y.; Zhang, J. H.; Peng, H. N.; Fan, H. L.; He, Y. B.; Gao, X. C. Adv. Funct. Mater. 2010, 20, 2448.

18. Benmansour, H.; Shioya, T.; Sato, Y.; Bazan, G. C. Adv. Funct. Mater. 2003, 13, 883.

19. Kim, K. S.; Jeon, Y. M.; Kim, J. W.; Lee, C. W.; Gong, M. S. Org. Electron. 2008, 9, 797.

20. Lee, H. S.; Jeon, Y. M.; Gong. M. S. J. Mater. Chem. 2010, 20, 10735.

21. Bongui, J. B.; Elomri, A.; Cahard, D.; Pfeiffer, B. Chem. Pharm. Bull. 2005, 53, 1540 .

22. Jeon, S. O.; Jeon, Y. M.; Kim, J. W.; Lee, C. W.; Gong, M. S. Org. Electron. 2008, 9, 522.

23. Jeon, Y. M.; Kim, J. W.; Lee, C. W.; Gong, M. S. Dyes Pigments $\mathbf{2 0 0 9}, 83,66$.

24. Jeon, S. O.; Jeon, Y. M.; Kim, J. W.; Lee, C. W.; Gong, M. S. Synth. Met. 2009, 159, 1147.

25. Kim, J. H.; Jeon, Y. M.; Jang, J. G.; Ryu, S.; Chang, H. J.; Lee, C. W.; Kim, J. W.; Gong, M. S. Bull. Korean Chem. Soc. 2009, 30, 647.

26. Jeon, S. O.; Lee, H. S.; Jeon, Y. M.; Kim, J. W.; Lee, C. W.; Gong, M. S. Bull. Korean Chem. Soc. 2009, 30, 863.

27. Kim, K. S.; Jeon, Y. M.; Kim, J. W.; Lee, C. W.; Gong, M. S. Dyes. Pigments 2009, 81, 174.

28. Jeon, S. O.; Jeon, Y. M.; Kim, J. W.; Lee, C. W.; Gong, M. S. Synth. Met. 2007, 157, 558.

29. Jeon, Y. M.; Lee, I. H.; Lee, C. W.; Gong, M. S. Bull. Korean Chem. Soc. 2009, 30, 863.

30. Salbeck, J.; Yu, N.; Bauer, J.; Weissörtel, F.; Bestgen, H. Synth. Met. 1997, 91, 209.

31. O’Brien, D. F.; Burrows, P. E.; Forrest, S. R.; Konne, B. E.; Loy, D. E.; Thompson, M. E. Adv. Mater. 1998, 10, 1108.

32. Salbeck, J.; Bauer, J.; Weissörtel, F. Macromol. Symp. 1997, 125, 121.

33. Jeon, S. O.; Jeon, Y. M.; Kim, J. W.; Lee, C. W.; Gong, M. S. Synth. Met. 2007, 157, 558.

34. Danel, K.; Huang, T. H.; Lin, J. T.; Tao, Y. T.; Chuen, C. H. Chem. Mater. 2002, 14, 3860.

35. Naphthalene, C.; Lee, W. Yang; Parr, R. G. Phys. Rev. B 1988, 37, 785.

36. Jeon, Y. M.; Lee, J. Y.; Lee, C. W.; Kim, J. W.; Gong, M. S. Org. Electron. 2010, 11, 1844.

37. Kim, S. K.; Yang, B.; Ma, Y.; Lee, J. H.; J. Y.; Park, J. W. J. Mater. Chem. 2008, 18, 3376.

38. Wen, S. W.; Lee, M. T.; Chen, C. H. J. Display Technol. 2005, 1, 90. 